\title{
USE OF ECG AND OTHER CLINICAL VARIABLES FOR DETECTING PULMONARY HYPERTENSION IN COPD PATIENTS- A CROSS-SECTIONAL OBSERVATIONAL STUDY
}

\author{
Asha Rangadham¹, Varun Dasegowdanapalya Gangaiah² \\ ${ }_{1}^{1}$ Assistant Professor, Department of General Medicine, Sanjay Gandhi Institute of Trauma and Orthopaedics. \\ ${ }^{2}$ Assistant Professor, Department of General Medicine, Sanjay Gandhi Institute of Trauma and Orthopaedics.
}

\begin{abstract}
BACKGROUND
ABSTRACT

Chronic Obstructive Pulmonary Disease (COPD) has emerged as a leading cause of mortality worldwide. Pulmonary Hypertension $(\mathrm{PH})$ is a frequent complication associated with COPD and it is prevalent among $10 \%-30 \%$ of the COPD patients with moderateto-severe disease. However, PH-associated with COPD is poorly diagnosed due to the lack of specific clinical investigations and sensitive markers. Despite being the most common techniques, the use of non-invasive techniques like echocardiography and electrocardiography for diagnosing PH in COPD is controversial.
\end{abstract}

\section{MATERIALS AND METHODS}

The cross-sectional observational study was conducted for a period of two years in a super speciality hospital in south India. The subjects were classified based on the status of PH. Apart from routine laboratory investigations, pulmonary function test, transthoracic 2D-echo with colour Doppler and electrocardiography were performed for all the participants. Different clinical and demographic variables were compared between COPD subjects with and without PH and their significance were studied.

\section{RESULTS}

The study included a total of 44 subjects with a mean age of $61.3 \pm 10.84$. PH was detected in 11 subjects based on the 2D ECHO Doppler findings. On comparison of the various ECG findings between the two groups, only $\mathrm{P}$ axis $>60^{0}(\mathrm{P}=0.0336)$ showed a significant variation and V1-R/ S > 1 (0.0507) showed a trend towards significance.

\section{CONCLUSION}

ECG may not be an accurate non-invasive tool for diagnosing PH in COPD patients.

\section{KEYWORDS}

COPD, Pulmonary Hypertension, Electrocardiography, Right Ventricular Hypertrophy.

HOW TO CITE THIS ARTICLE: Rangadham A, Gangaiah VD. Use of ECG and other clinical variables for detecting pulmonary hypertension in COPD patients- a cross-sectional observational study. J. Evolution Med. Dent. Sci. 2018;7(02):167-170, DOI: $10.14260 /$ jemds/2018/37

\section{BACKGROUND}

Chronic obstructive pulmonary disease (COPD) is the most prevailing cause of mortality worldwide. ${ }^{1}$ According to the 2013 report by World Health Organisation, 65 million people have moderate-to-severe COPD globally. The disease is estimated to cause more than $30 \%$ total deaths by the next 10 years and it is projected to become the third leading cause of death worldwide by $2030 .{ }^{2}$ Reports indicate that $90 \%$ of the COPD deaths occur in the low- and middle-income countries. ${ }^{3}$

A population-based survey has reported an overall prevalence of 8.2 in the Chinese population and the disease was found to be prevalent among individuals of 40 years of age. ${ }^{4}$ Studies based on Indian population have reported that 30 million Indians suffer from COPD. ${ }^{5}$ A review of the Indiabased population studies by Jindal et al have reported that the estimated prevalence of COPD is 5\% in men and $2.7 \%$ in women. ${ }^{6} \mathrm{~A}$ systemic review has found that the prevalence of chronic bronchitis in the rural Indian population ranges between $6.5 \%$ and $7.7 \% .^{7}$

'Financial or Other Competing Interest': None.

Submission 23-11-2017, Peer Review 17-12-2017,

Acceptance 23-12-2017, Published 08-01-2018.

Corresponding Author:

Varun Dasegowdanapalya Gangaiah,

\#137, Sahyadri, $7^{\text {th }}$ Cross, $4^{\text {th }}$ Main Road,

Chamarajpet, Bengaluru-560018.

E-mail: varun.dg@gmail.com

DOI: $10.14260 /$ jemds $/ 2018 / 37$

Pulmonary hypertension $(\mathrm{PH})$ is a frequent complication noted in patients with COPD, which further increases the risk of disease exacerbation and decreases the survival. ${ }^{8} \mathrm{PH}$ is reported to be prevalent among $10 \%-30 \%$ of the patients with moderate-to-severe COPD. ${ }^{9}$ Though PH associated with COPD is a well-recognised entity, it confers poor diagnosis. Moreover, the precise estimation of the incidence of $\mathrm{PH}$ is difficult since most of the cases have been reported in patients with advanced COPD disease. ${ }^{10}$

Studies have reported the lack of specific clinical investigations and sensitive markers to accurately distinguish COPD patients with PH. ${ }^{9}$ Echocardiography and electrocardiography are the two commonly used techniques for the diagnosis of PH. The principal non-invasive technique employed for the diagnosis of COPD is electrocardiography (ECG), but the method holds technical limitations in a significant portion of the COPD patients. Several studies have noted variations like longer PR interval, taller R-wave in lead I, leftward deflection in the T-wave axis, incomplete right bundle branch and larger S-wave in lead I for COPD patients with PH.9,11 There are contradictory findings on the efficacy of ECG in distinguishing COPD patients with PH. Alkukhun et al have reported that ECG can significantly distinguish between advanced COPD patients with $\mathrm{PH}$ and those without PH. ${ }^{11}$

There is a lack of clear consensus to differentiate COPD patients with and without PH. The present study was conducted to compare clinical and demographic variables 
among COPD patients with and without pulmonary hypertension, and to explore the risk associated with different variables in COPD patients with $\mathrm{PH}$.

\section{MATERIALS AND METHODS}

The 2-year cross-sectional observational study included both male and female inpatients diagnosed with COPD at a super specialty hospital in south India. The diagnosis of COPD was made as per World Health Organisation definition and evidence of pulmonary function tests. The study was approved by the Institutional Ethics Committee and informed consents were obtained from all the participants. Subjects with diabetes mellitus, hypertension, pulmonary diseases like bronchial asthma, tuberculosis, suppurative lung diseases, restrictive lung diseases, interstitial lung diseases and heart diseases like congenital heart disease, valvular heart disease and coronary heart disease were excluded.

Detailed history was collected and clinical examination of the subjects were performed using a structured proforma. Routine investigations carried out for all the subjects included: haemoglobin, total count, differential count, erythrocyte sedimentation rate and urine examination. Pulmonary function test (PFT), reversible airway test and transthoracic 2D-echo with colour Doppler and electrocardiography (12-lead) were also performed for all the participants. The ECG parameters considered for computation were: P-wave axis $>60^{\circ}$, P-pulmonale, $\mathrm{QRS}$ axis $>90^{\circ}$, lead V1-R/ S > 1, lead V6-R/ S > 1, clockwise rotation, intrinsicoid deflection and ST-T changes.

Computerised spirometry was performed using KIT MICRO, Data Management Software Version 6.1 A. Among the PFT parameters, forced expiratory volume in one second/forced vital capacity (FEV1/FVC) ratio and forced expiratory volume in one second (FEV1) were analysed. Transthoracic 2D-echo with colour Doppler was performed using H. P. SONOS 2000, system No. 2406A (HP, US). Patients were considered to have right ventricle/ right atrium (RV/RA) dilated or right ventricular hypertrophy (RVH) if the right ventricle (RV) thickness was $5 \mathrm{~mm}$ or more and right atrial enlargement (RAE) if right atrial diameter (inferiorsuperior) was $5.5 \mathrm{cms}$ or more. The evidence of PAH was looked for with Doppler studies. The subjects were classified into two groups based on the presence and absence of PH.

\section{Statistics}

Data with normal distribution are represented as mean \pm SD and those without normal distribution as median (range) and categorical data as counts. The variables with normal distribution were compared by independent ' $t$ ' test and without normal distribution by Mann-Whitney $U$ test and categorical variables by chi-square test. The risk estimate done by odds ratio was also verified. $\mathrm{P}$ value $<0.05$ was considered statistically significant. All the statistical analysis was performed using MedCalc Software Version 14.8.1.

\section{RESULTS}

Out of the 50 enrolled subjects, 6 were excluded due to the lack of sufficient data. A total of 44 subjects with COPD were included in the study. The mean age of the subjects was 61.3 \pm 10.84 with a male-to-female ratio of $1: 0.22$. The average duration of illness was 6 years, ranging from $2-20$ years. Among the subjects, 11 were found to be positive for $\mathrm{PH}$ and
33 were negative based on 2D ECHO Doppler findings. The comparison of demographic and clinical variables of the $\mathrm{PH}$ positive and negative groups are provided in Table 1.

Upon comparison the variables like FEV1/ FVC ratio, $\mathrm{RV} / \mathrm{RA}$ dilated or $\mathrm{RVH}$ and $\mathrm{P}$ axis $>60^{\circ}$ were noted to differ significantly between the two groups. Additionally, V1-R/ S>1 ( $P$ value of 0.05 ) showed a trend towards significance. However, other variables like age, gender, duration of illness, smoking, FEV1, P-pulmonale, QRS axis > 900, V6-R/ S>1, clockwise rotation, intrinsicoid deflection and ST-T changes showed uniform distribution.

FEV1/ FVC was significantly higher in subjects with positive $\mathrm{PH}(57.61 \pm 12.29)$ than those with negative $\mathrm{PH}$ $(47.21 \pm 13.02)(P=0.025)$. A significantly higher number of subjects with RV/ RA-Dilated or RVH belonged to the group without $\mathrm{PH}(\mathrm{n}=28)(<0.0001)$. None of the subjects with $\mathrm{PH}$ had RV/ RA-dilated or RVH. Similarly, P axis was $>60^{\circ}$ in a significant number of subjects belonging to the $\mathrm{PH}$ positive group $(n=10)$ and was $<60^{\circ}$ in a significant number of subjects belonging to the $\mathrm{PH}$ negative group $(\mathrm{n}=17)$ $(\mathrm{P}=0.0336)$. V1-R/ $\mathrm{S}$ was $>1$ and $<1$ majorly in subjects negative for $\mathrm{PH}(\mathrm{n}=12$ and $\mathrm{n}=21)$, but was not statistically significant.

\begin{tabular}{|c|c|c|c|}
\hline Factors & $\begin{array}{c}\text { PH } \\
\text { Positive } \\
(\mathrm{N}=11)\end{array}$ & $\begin{array}{c}\text { PH } \\
\text { Negative } \\
(\mathrm{N}=33)\end{array}$ & $P$ value \\
\hline Age & $62.0 \pm 12.1^{*}$ & $61.0 \pm 10.5^{*}$ & 0.7764 \\
\hline Gender (M/F) & $10 / 1$ & $26 / 7$ & 0.6517 \\
\hline Duration of Illness & $5(3-10) \#$ & $6(2-20) \#$ & 0.0805 \\
\hline Smoking (Y/N) & $10 / 1$ & $23 / 10$ & 0.3149 \\
\hline FEV1 & $1.15 \pm 0.41^{*}$ & $1.06 \pm 0.26^{*}$ & 0.4088 \\
\hline FEV1/ FVC & $57.61 \pm 12.29 *$ & $47.21 \pm 13.02^{*}$ & 0.025 \\
\hline $\begin{array}{l}\text { RV/ RA-Dilated } \\
\text { or RVH }(\mathrm{Y} / \mathrm{N})\end{array}$ & $0 / 11$ & $28 / 5$ & $<0.0001$ \\
\hline P-pulmonale $(\mathrm{Y} / \mathrm{N})$ & $3 / 8$ & $14 / 19$ & 0.5918 \\
\hline $\mathrm{P}$ axis $>60^{\circ}(\mathrm{Y} / \mathrm{N})$ & $10 / 1$ & $16 / 17$ & 0.0336 \\
\hline QRS axis $>90^{\circ}(\mathrm{Y} / \mathrm{N})$ & $7 / 4$ & $16 / 17$ & 0.6011 \\
\hline V1-R/ S >1 (Y/N) & $0 / 11$ & $12 / 21$ & 0.0507 \\
\hline V6-R/ S >1 (Y/N) & $3 / 8$ & $13 / 20$ & 0.7174 \\
\hline $\begin{array}{c}\text { Clockwise rotation } \\
(\mathrm{Y} / \mathrm{N})\end{array}$ & $1 / 10$ & $8 / 25$ & 0.5174 \\
\hline $\begin{array}{c}\text { Intrinsicoid } \\
\text { deflection }(\mathrm{Y} / \mathrm{N}) \\
\end{array}$ & $6 / 5$ & $10 / 23$ & 0.2776 \\
\hline ST-T changes $(\mathrm{Y} / \mathrm{N})$ & $1 / 10$ & $7 / 26$ & 0.6517 \\
\hline
\end{tabular}

Table 1. Comparison of Demographic and Clinical Variables in Subjects With and Without $P H$

${ }^{*}$ mean $\pm \mathrm{SD}$, \# median (range).

No significant association was noted on comparison of variables like age, gender, smoking, FEV1/ FVC and Ppulmonale in COPD patients with PH (Table 2). However, the incidence of $\mathrm{PH}$ was found to be 4.35 times higher in smokers than non-smokers. Males were $63 \%$ less likely than females to be associated with $\mathrm{PH}$. Three patients had normal FEV1/FVC ratio ( $>=70 \%$ ) and hence were excluded from the analysis. The incidence of $\mathrm{PH}$ was found to be $61 \%$ lesser in the FEV1/ FVC ratio $<50 \%$ or severe group when compared to mild-to-moderate group. Presence of P-pulmonale was found to be $49 \%$ less likely to be associated with $\mathrm{PH}$ than its absence. There was no difference in the incidence of $\mathrm{PH}$ across different age groups ( $<=35$ to $<=60$ and $>60$ ). 


\begin{tabular}{|c|c|c|c|}
\hline Factors & $\begin{array}{l}\text { Odds } \\
\text { Ratio }\end{array}$ & $\begin{array}{c}\text { 95\% Confidence } \\
\text { Interval }\end{array}$ & $P$ value \\
\hline \multicolumn{4}{|c|}{ Age } \\
\hline$>60$ & 1 & \multirow[t]{2}{*}{0.2540 to 3.9371} & \multirow[t]{2}{*}{1} \\
\hline$<=35$ to $<=60$ & 1 & & \\
\hline \multicolumn{4}{|c|}{ Gender } \\
\hline Male & 0.3714 & \multirow[t]{2}{*}{0.04040 to 3.4152} & \multirow[t]{2}{*}{0.3816} \\
\hline Female & 1 & & \\
\hline \multicolumn{4}{|c|}{ Smoking } \\
\hline Yes & 4.3478 & \multirow[t]{2}{*}{0.4887 to 38.6791} & \multirow[t]{2}{*}{0.1875} \\
\hline No & 1 & & \\
\hline \multicolumn{4}{|c|}{ FEV1/ FVC } \\
\hline Severe & 0.3889 & \multirow{2}{*}{0.08238 to 1.8359} & \multirow{2}{*}{0.233} \\
\hline $\begin{array}{l}\text { Mild and } \\
\text { Moderate }\end{array}$ & 1 & & \\
\hline \multicolumn{4}{|c|}{ P-Pulmonale } \\
\hline Yes & 0.5089 & \multirow[t]{2}{*}{0.1140 to 2.2712} & \multirow[t]{2}{*}{0.3761} \\
\hline No & 1 & & \\
\hline $\begin{array}{r}\text { Table 2. Risk } \\
V(x)\end{array}$ & $\begin{array}{l}\text { imate } 0 \\
\text { bles in }\end{array}$ & $\begin{array}{l}\text { emographic and } C \\
\text { jects with } P H\end{array}$ & nical \\
\hline
\end{tabular}

\section{DISCUSSION}

The incidence of PH noted in the current study in COPD patients was around $25 \%(n=11)$. The recent studies conducted in south Indian population by Reddy et al (2016) and Mahishale et al (2015) have reported a higher frequency of PH in COPD patients. ${ }^{12,13}$ The prevalence reported by Reddy et al was $50 \%$ and by Mahishale et al was $41.96 \%$ (involving 2040 COPD patients). Researchers have noted that frequency and degree of $\mathrm{PH}$ is directly proportional to the severity of COPD. ${ }^{12,13}$ Reddy et al have found that $\mathrm{PH}$ accounted for $83 \%$ in subjects with severe COPD compared to only $24 \%$ in those with mild COPD. ${ }^{12}$ However, the present study did not observe a similar trend.

COPD patients with $\mathrm{PH}$ are more susceptible to death due to increased risk of right heart failure with systemic congestion. The disease is also associated with ankle oedema, inability of the right ventricular output to meet the peripheral demand during exercise, renal problems and other

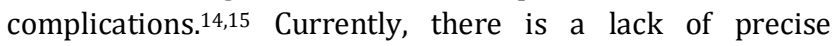
treatment and effective cure for the disease. ${ }^{15}$ Dave et al have indicated COPD as a late onset disease. They have also noted that maximum number of COPD patients belonged to the 5160 years' age group with a mean age of $54.8 \pm 5$ years. ${ }^{16}$ The mean age noted by Soliman et al (2015) was $62 \pm 9.16$ years. ${ }^{17}$ In concurrence with their findings, the present study has noted a mean age of $61.3 \pm 10.84$ years in COPD patients. Compared to other studies, Sertogullarindan et al have reported a higher mean age of $67 \pm 10$ years. ${ }^{18}$

India-based population studies have noted a higher prevalence of COPD in males due to the increased use of tobacco. The present study has also found increased occurrence of COPD in male subjects (82\%) than females $(18 \%)$. The prevalence reported by Reddy et al and Mahishale et al in male patients were $85 \%$ and $74 \%$ respectively.12,13 However, studies have indicated that female mortality associated with COPD has surpassed men in countries like US and Turkey, where smoking is more common in females. ${ }^{18_{2} 19}$ Joppa et al (2006) have concluded that the results of the pulmonary function test like FEV1 and FEV1/ FVC ratio did not differ significantly between COPD subjects with and without PH. ${ }^{20}$ Similarly, the current study results of FEV1 did not differ significantly between COPD subjects with and without PH. Whereas, Sertogullarindan et al (2012) have highlighted the significant role of FEV1 \% in the development of $\mathrm{PH}$ in moderate and very severe COPD subjects. ${ }^{18}$ The study by Joppa and Colleagues observed lower FEV1 in patients with $\mathrm{PH}$ than those without the condition with a trend towards significance $(\mathrm{P}=0.052) .20$ A similar observation was also noted by Fayngersh et al.21 Contrary to the observation of Joppa et al, the present study has noted a significantly higher FEV1/ FVC ratio (57.61 \pm 12.29$)$ in COPD patients with $\mathrm{PH}$. PH-positive subjects demonstrated a mean moderate FEV1/ FVC ratio, whereas those without PH had a mean severe FEV1/ FVC ratio. This observation correlates well with the previous study finding. A similar study conducted by Keller and Colleagues on 89 patients with COPD has shown that COPD patients without PH had significantly higher $(<0.001)$ mean FEV1/ FVC ratio $(53 \pm 11)$ compared to COPD patients with $\mathrm{PH}(43 \pm 11) .22$

Sertogullarindan et al (2012) and Fayngersh et al (2011) have suggested gender as an independent predictor of $\mathrm{PH}$ in COPD. ${ }^{18,21}$ The present study has also noticed gender as an independent risk factor for the development of $\mathrm{PH}$ in subjects with COPD. However, males were noted to be $63 \%$ less likely to be associated with $\mathrm{PH}$ than females. This observation is in line with the study by Sertogullarindan et al, which reported a higher frequency of PH in females than males with COPD.18

Current study has also concluded age and smoking as independent factors for predicting the risk for PH in COPD patients. This is in agreement with the study of Fayngersh et al (2011). ${ }^{21}$ The present study has found that smokers were 4.3 times more likely to be associated with $\mathrm{PH}$ than nonsmokers.

The present study has concluded ECG as an insensitive tool for diagnosing PH in COPD patients. Among the various ECG parameters, only $P$ axis of $>60^{\circ}$ was noted in a significant number of subjects with $\mathrm{PH}$. In contrast, the study by Alkukhun et al (2014) did not find any significant difference in the P-wave axis of COPD patients with and without PH. The study also noted a uniform distribution of V1-R/ S ratio and no significant difference in the QRS axis between COPD subjects with and without PH, similar to the current study. ${ }^{11}$ Several previous studies have indicated ECG as an inadequate tool with poor sensitivity for diagnosing $\mathrm{PH}$ in COPD. 11,23

Literature evidence indicate that the PH may increase the possibility of right ventricular hypertrophy in subjects with COPD. ${ }^{9}$ Whereas, the present study has noted RVH only in a significantly lesser number of subjects with PH. Diagnosis of $\mathrm{PH}$ in COPD patients is often challenging, as most of the patients might be stable and they do not undergo right heart catheterisation. Moreover, the similarity in symptoms for both the diseases adds to the difficulty in diagnosing $\mathrm{PH}$. Early detection is crucial to improve the treatment outcome and quality of life. ${ }^{14}$

The major limitations of the present study include singlecentre-based evaluation and small sample size. The reduced sample size and single-centre evaluation limit the generalisability of the study findings. Moreover, the study has not used right heart catheterisation, which is considered as the Gold standard for evaluating PH. The preliminary study warrants more similar cross-sectional studies involving large sample size to substantiate the findings, thereby to identify precise diagnostic markers for the detection of $\mathrm{PH}$. 


\section{CONCLUSION}

In summary, the present study corroborating the increased incidence of PH in COPD patients, especially in male subjects underscores the need of non-invasive markers for the precise and sensitive detection of the condition. The findings also suggest ECG is not a reliable marker for PH detection.

\section{REFERENCES}

[1] Devine JF. Chronic obstructive pulmonary disease: an overview. Am Health Drug Benefits 2008;1(7):34-42.

[2] WHO. Burden of COPD. 2017 http://www.who.int/respiratory/copd/burden/en/

[3] WHO. Chronic Obstructive Pulmonary Disease (COPD) WHO. 2017. http://www.who.int/mediacentre/factsheets/fs315/e $\mathrm{n} /$

[4] Zhong N, Wang C, Yao W, et al. Prevalence of chronic obstructive pulmonary disease in China: a large, population-based survey. Am J Respir Crit Care Med 2007;176(8):753-60.

[5] Salvi S, Agrawal A. India needs a national COPD prevention and control programme. J Assoc Physicians India 2012;60 Suppl:5-7.

[6] Jindal SK, Aggarwal AN, Gupta D. A review of population studies from India to estimate national burden of chronic obstructive pulmonary disease and its association with smoking. Indian J Chest Dis Allied Sci 2001;43(3):139-47.

[7] McKay AJ, Mahesh PA, Fordham JZ, et al. Prevalence of COPD in India: a systematic review. Prim Care Respir J 2012;21(3):313-21.

[8] Chaouat A, Naeije R, Weitzenblum E. Pulmonary hypertension in COPD. Eur Respir J 2008;32(5):137185.

[9] Elwing J, Panos RJ. Pulmonary hypertension associated with COPD. Int J Chron Obstruct Pulmon Dis 2008;3(1):55-70.

[10] Pulmonary hypertension in chronic obstructive pulmonary disease: diagnosis and management | advances in PH Journal | PHA 2017. http://www.phaonlineuniv.org/Journal/Article.cfm?It emNumber $=774$

[11] Alkukhun L, Baumgartner M, Budev $M$, et al. Electrocardiographic differences between COPD patients evaluated for lung transplantation with and without pulmonary hypertension. COPD 2014;11(6):670-80.
[12] Reddy S, Rajender, Reddy N. Prevalence of pulmonary hypertension in copd patients: a retrospective observational study. Int J Intg Med Sci 2016;3(5):2859.

[13] Mahishale V, Patil B, Rathi A, et al. Screening of Chronic Obstructive Pulmonary Disease patients for pulmonary arterial hypertension using twodimensional transthoracic doppler echocardiography in tertiary care hospital in India. Heart India 2015;3(3):66-71.

[14] Ferreira LM. COPD with pulmonary hypertension pulmonary hypertension news. 2017. https://pulmonaryhypertensionnews.com/copdpulmonary-hypertension/

[15] Barberà JA, Peinado VI, Santos S. Pulmonary hypertension in chronic obstructive pulmonary disease. Eur Respir J 2003;21(5):892-905.

[16] Dave L, Garde S, Ansari OA, et al. A study of association between metabolic syndrome and COPD. Journal of Evolution of Medical and Dental Sciences 2014;3(22):6183-8.

[17] Soliman M, Heshmat H, Amen Y, et al. Detection of right sided heart changes and pulmonary hypertension in COPD patients. Egyptian Journal of Chest Diseases and Tuberculosis 2015;64(2):335-41.

[18] Sertogullarindan B, Gumrukcuoglu HA, Sezgi C, et al. Frequency of pulmonary hypertension in patients with COPD due to biomass smoke and tobacco smoke. Int J Med Sci 2012;9(6):406-12.

[19] Han MK, Postma D, Mannino DM, et al. Gender and chronic obstructive pulmonary disease. Why it matters? Am J Respir Crit Care Med 2007;176(12):1179-84.

[20] Joppa P, Petrasova D, Stancak B, et al. Systemic inflammation in patients with COPD and pulmonary hypertension. Chest 2006;130(2):326-33.

[21] Fayngersh V, Drakopanagiotakis F, McCool DF, et al. Pulmonary hypertension in a stable community-based COPD population. Lung 2011;189(5):377-82.

[22] Keller CA, Shepard JW, Chun DS, et al. Pulmonary hypertension in chronic obstructive pulmonary disease: multivariate analysis. Chest 1986;90(2):18592.

[23] Stockley RA, Rennard SI, Rabe K, et al. Chronic obstructive pulmonary disease: a practical guide to management. John Wiley \& Sons 2008; p. 917. 